\title{
Adaptive centre extraction method for structured light stripes
}

\author{
${ }^{1,2}$ Zhixin $\mathrm{Hu},{ }^{1}$ Hongtao Zhu, ${ }^{3}$ Ming Hu and ${ }^{4}$ Yong Ma \\ ${ }^{1}$ School of Mechanical and Electrical Engineering, Nanchang University, \\ Nanchang, Jiangxi Province, China \\ ${ }^{2}$ School of Mechanical and Vehicular Engineering, Nanchang Institute of Science \\ and Technology, Nanchang, Jiangxi Province, China \\ ${ }^{3}$ School of Electronic Engineering, Nanchang Institute of Science and Technology, \\ Nanchang, Jiangxi Province, China \\ ${ }^{4}$ Electronic Information School, Wuhan University, Wuhan, Hubei Province, China
}

Received: 13.04 .2016

After revision: 08.11.2016

\begin{abstract}
In the vision systems based on structured light, accurate extracting of centre positions of a light stripe represents one of the key points in solving the whole measurement task. Usually, high radiant illumination and objects with abundant surface textures decrease the detection precision. To address these problems, we suggest an adaptive centre-extraction method. First, it improves the image contrast using a novel adaptive threshold-based power transformation. Second, pixel-level centre points are obtained with our adaptive dual-threshold Canny's edge detection method. Finally, subpixel-level centre points are extracted using a Hessian matrix for a limited number of pixels. Our experiments prove robustness and practicability of the method, which can cope with complex surface textures of projected objects and high radiant illumination.
\end{abstract}

Keywords: structured light, radiant illumination, centre extraction, power transform, Hessian matrix.

PACS: $42.30 . \mathrm{Tz}$

UDC: 004.932

\section{Introduction}

Structured light measurements are widely used for inspection and quality control of many processes in industry. The advantages of those measurements are high precision and fast processing [1]. Generally, the structured light measurement system is composed of a CCD camera, a laser projector and computers [2,3]. The laser produces a structured light and projects it onto an object measured, so that a laser light stripe is formed at the surface. Then the image of the object and the stripe is captured by the CCD camera. Subpixel-level central positions of the laser stripe are deduced using some extraction algorithms. Finally, a 3D character of the object is calculated issuing from the central positions [4]. Here a key step is to extract the central positions of the laser stripe accurately and efficiently [5 - 6]. In any real applications, the surfaces of the objects are textured, and the radiation intensity of the scene is relatively high, thus leading to reduced contrast and distorted image. Because of complex textures and high illumination, it is difficult to distinguish between the structured light strips and the background, and to find centre positions. This is why extracting of the centre positions is a key point of the structured light measurements.

Currently, the methods aimed at extracting centre positions for the structured light stripes involve two steps, the image preprocessing and the centre extraction itself. The image preprocessing methods, e.g. an Otsu's method [8, 9], a filtering [10], a histogram equalization [11]

Ukr. J. Phys. Opt. 2017, Volume 18, Issue 1 
and an edge detection [12], mainly improve the contrast of image and filter its noise. The centre extraction methods are aimed at obtaining the centre positions of light stripes. They include the methods of extreme value [13,14], threshold [15-17], directional template [18-20], grey centroid [21,22], curve fitting [23, 24] and Hessian matrix [25-27]. Below we discuss in brief these methods and point to their advantages and shortcomings.

The Otsu's method [9] is very sensitive to image contrast and size of the object under test. It produces good segmentation results only for grey-scale images with a single peak. When the grey levels of object and background are similar, one obtains multiple peaks of the image of the former and the fuzzy boundaries of the latter. Then it is difficult to judge about the boundaries of the laser stripe using the Otsu's method. The filtering methods [10] are only suitable for the Gauss and mixed noises and so, in actual measurements, they are susceptible to low-contrast conditions. The histogram equalization [11] represents a method for correcting the grey-transform function. Here the image can become clearer with the uniform probability distribution of grey levels, but the method can lose some image details. The edge-detection methods [12] can extract light stripe boundaries fairly well, but there is a high possibility of degrading precision of the edge detection. Moreover, all of the methods mentioned above have some serious requirements, e.g. a top-quality surface texture and a suitable radiant illumination in the images. When the surface texture is complicated and the radiant illumination high, these methods cannot avoid lowering the extraction accuracy.

The extreme-value method $[13,14]$ implies choosing the pixels with the maximum grey values on the laser stripe as the centre positions. The method is fast and accurate when the light stripe obeys ideal Gaussian distribution and the other areas of image are dark, but it is susceptible to noise and contrast conditions. The threshold method [15-17] sets a boundary threshold to obtain two borders in the transverse section of the light stripe, and the centres of the light stripe are regarded as centres of the two borders. This method is affected by the noise and the image contrast conditions, too. The directional-template method [18-20] convolves $0^{\circ}, 90^{\circ}$, and $45^{\circ}$ directional templates with the light stripe of image. The extreme pixels in the transverse section of the light stripe are strengthened after convolution, while the other surrounding points are suppressed. The point with the maximum value is a section centre of the light stripe. This method repairs disconnected lines of the light stripe and suppresses noise, but also increases the amounts of computation and data storage. The grey-centroid method [21,22], which directly calculates the maximum greyscale point as the centre position of the light stripe, is as sensitive to noises as the extreme-value method. Since the extraction accuracy is affected by the curvature of the light stripe, the grey-centroid method is generally used for the light stripes with small curvatures.

The curve-fitting method $[23,24]$ outlines the grey-scale distribution of the transverse section of the light stripe, employing a Gaussian curve or a parabola. The central point of the transverse section is a local maximum of the fitted curve. Since the method is valid only for the wide stripes with constant directions, the extreme points found often deviate from the actual central points. Finally, the Hessian matrix method determines the centre of the light stripe by analyzing eigenvalues of the Hessian matrix for different candidate feature points. The centres of the light stripes are distinguished by the features of the two eigenvalues of the Hessian matrix, and the subpixel centre coordinate of the light stripe is computed by implementing Taylor expansion in the normal-vector direction. The method is known for its immunity to noise, high accuracy and robustness [25-27] and manifests advantages when processing the images of complex environment. It uses eigenvalue thresholds for adapting different light stripes and extracts subpixel-level centre positions of the centres of light stripes. Nonetheless, the method often extracts false centre points, 
or misses true ones. Moreover, the amount of computation is larger than that needed for the other methods scrutinized above.

When seeking for easily adaptive and accurate enough methods for extracting the centre positions of the light stripes, aimed at inspection and quality control in industry, it would be reasonable to direct efforts to complex surface textures of objects and dynamic radiant illumination. Below we present a normalization model able to enhance the contrast between the light stripe and the background, and reduce noise in the image. It is used to extract the subpixel-level centre positions of light strips in adaptive manner.

\section{Centre extraction for structured light stripes}

\subsection{Image preprocessing based on adaptive power transform}

Power transform is a method for enhancing image contrast. The traditional power transform algorithm is described as follows:

$$
y=x^{\lambda}
$$

where $x$ represents the original pixel level, $y$ its 'enhanced' value, and $\lambda$ the exponent. Generally, $\lambda$ is fixed and performs well while enhancing the image contrast. However, the surface texture and the radiant illumination are changing in any practical task of inspection and quality control in industry, which degrades the performance of the power transform with fixed $\lambda$. Therefore an adaptive $\lambda$ parameter is necessary, where different $\lambda$ should be used for different input images. In practical applications, the pixel values of the light strips are higher than those of the background, and can be enhanced further by the power-transform algorithm. When the intensity of the light strips is relatively large, larger $\lambda$ are needed to enhance it and, vice versa, smaller $\lambda$ can be used when the light strips have lower intensities. In this work, we introduce a signal-to-noise ratio to evaluate the intensity of the light strips as follows:

$$
\xi=10 \lg \frac{\mu}{\sigma}
$$

where $\xi$ denotes a scalar signal-to-noise ratio for the original image, $\mu$ the mean grey level of all pixels, and $\sigma$ the standard deviation for that image.

Then the adaptive $\lambda$ value can be calculated in the form of polynomial of the variable $\xi$ :

$$
\lambda(\xi)=\left\{\begin{array}{c}
a_{1} \xi^{4}+a_{2} \xi^{3}+a_{3} \xi^{2}+a_{4} \xi+a_{5}, \xi \leq T . \\
\lambda(T), \text { otherwise }
\end{array}\right.
$$

Here $a_{1}, a_{2}, a_{3}, a_{4}$ and $a_{5}$ are polynomial coefficients, and $T$ and $\lambda_{\text {constant }}$ the thresholds used to avoid over-enhancement. Therefore, the adaptive power transform can be described as

$$
y=x^{\lambda(\xi)} .
$$

Different polynomial coefficients in Eq. (3) are necessary for different industrial applications, which can be estimated using a standard regression analysis.

In brief, our procedure is performed into four steps: (1) capturing training images, (2) calculating $\xi$ for each of these images, (3) obtaining optimal exponent $\lambda$ for each image, and (4) calculating $a_{1}, a_{2}, \ldots, a_{5}$ with the regression analysis. In this study, we have captured 15 light strip images associated with rail wear measurements. The optimal exponents $\lambda$ found according to the above procedure are shown in Fig. 1, along with the corresponding signal-to-noise ratios. 


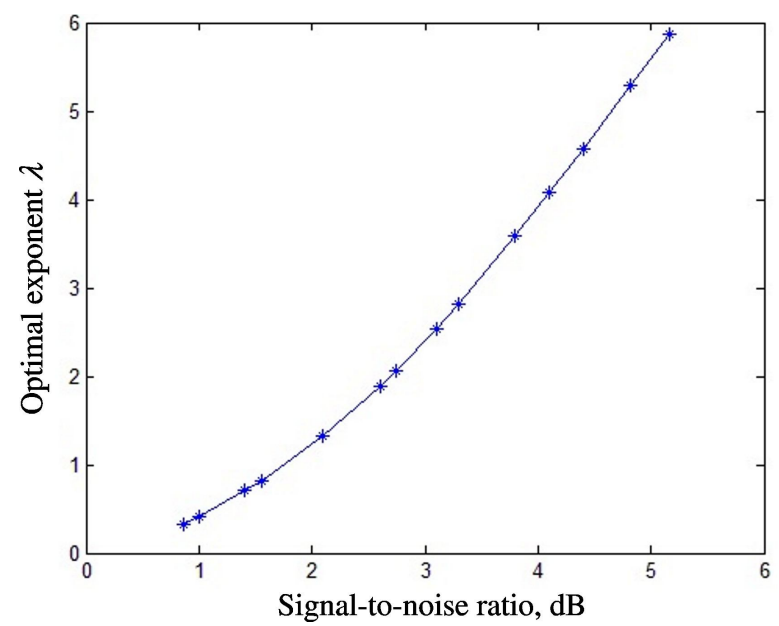

Fig. 1. Dependence of optimal exponent on signal-to-noise ratio.

As a result, the empirical formula for $\lambda$ is obtained:

$$
\lambda(\xi)=\left\{\begin{array}{c}
-0.0064 \xi^{4}+0.0605 \xi^{3}-0.0212 \xi^{2}+0.5421 \xi-0.1542, \xi<5 \\
5.89, \text { otherwise }
\end{array}\right.
$$

When the signal-to-noise ratio is less than $5 \mathrm{~dB}$, the power-law parameter should be set lower as the signal-to-noise ratio decreases $(\lambda<5.89)$. When this ratio is larger than $5 \mathrm{~dB}$, a fixed $\lambda$ can be used. Here the optimum is equal to $\lambda=5.89$.

\subsection{Adaptive light-stripe edge detection}

Currently, the main methods for detecting the edges of the structured light stripes are those named after Robert, Prewitt, Sobel and Canny [28, 29]. The Robert operator calculates the difference between the orthogonal pixels. It is better for detecting vertical edges than hypotenuse ones and, moreover, it suffers significantly from noises. The Prewitt operator simply considers the pixels with the differences larger than a given threshold as the edges, so that it can generate some misjudged edges. The Sobel operator that convolves the original image with a weighted $3 \times 3$ matrix to suppress edge blur is not efficient when being applied to the structured stripes with backgrounds.

The Canny operator can both smooth the image and identify the real light stripe edges. In its canonical version, the Canny edge detection method uses a couple of fixed thresholds to detect the stripe edges, where the upper threshold detects the edges in the image and the lower one mends the breakpoints. However, fixed thresholds are not suitable for extracting light stripes under varying illumination conditions. Hence, the thresholds should be set adaptively. Here we introduce the Otsu's method to modify the Canny operator and select the thresholds adaptively. Since the images processed with the Canny operator can be divided into two classes, the edges and the backgrounds, the Otsu's method can calculate a threshold that separates the image into those classes, using the criteria of intra-class and inter-class variances. Then the threshold obtained with the Otsu's method can be used as the upper threshold of the modified Canny algorithm. Thus, the upper threshold $T_{\text {upper }}$ of our modified Canny algorithm is given by

$$
T_{\text {upper }}=k T_{\text {Otsu }}
$$

where $T_{\text {Otsu }}$ is obtained with the Otsu's method from the image processed by the Canny operator 
and $k$ ranges from 0.4 to 1.0 for different industrial applications.

Having obtained the upper threshold adaptively, we can set the lower threshold as some proportion of the upper one. In this study, we set the above proportion to be $1 / 4$, basing on our experience. In other words, we obtain $T_{\text {lower }}=T_{\text {upper }} / 4$ for the lower threshold $T_{\text {lower }}$. Owing to adaptive searching for both the upper and lower thresholds, our modified Canny method detects efficiently the stripe edges and is robust to noises. In Fig. 2 we compare the results obtained with our method and a number of methods known from the literature. Then we can obtain a pixel-level centre line in the middle of the neighbouring edges.
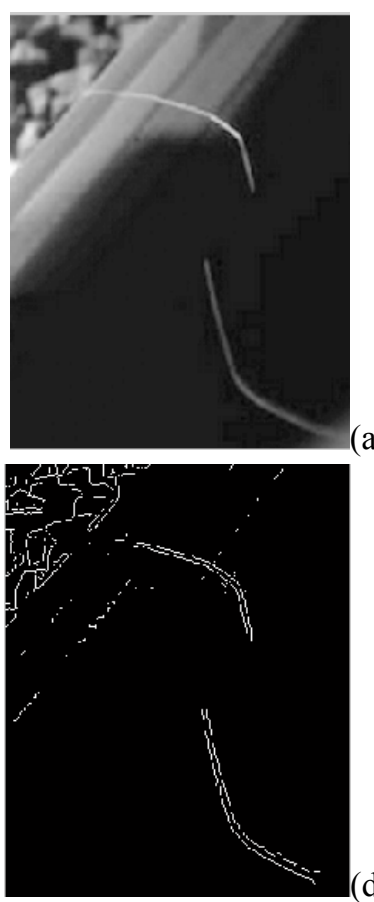
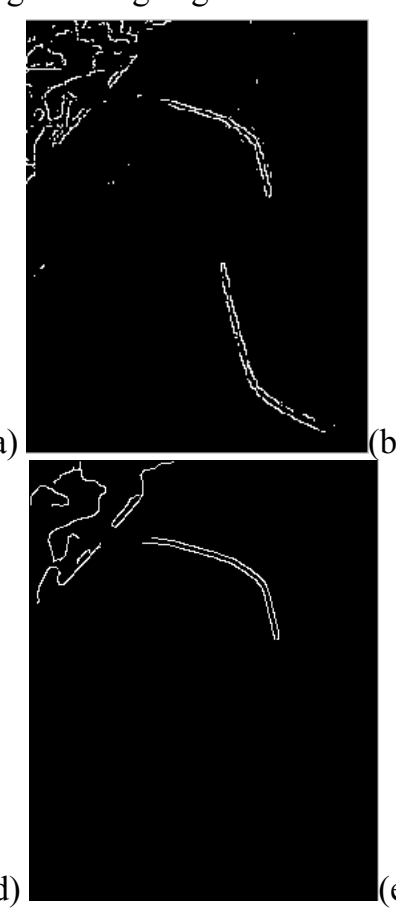
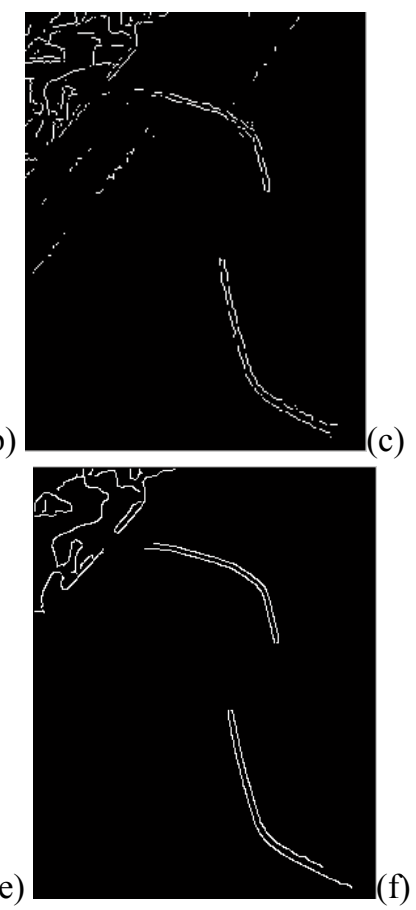

Fig. 2. Comparison of different methods for detecting stripe edges. Panels (a)-(f) correspond to the original image and the images processed with the methods by Robert (b), Prewitt (c), Sobel (d), and Canny (e) (with fixed threshold), and with our adaptive method (f).

\subsection{Centre extraction method}

In many industrial inspections, the light intensity characteristic for the cross section of the light stripe is such that the intensity is the highest in its centre and gets lower towards the edges, thus obeying approximately the Gaussian distribution. The normalized intensity distribution for the light stripe is shown in Fig. 3. We remind that a pixel-level centre line of the light stripe has already been extracted with our improved Canny operator (see Section 2.2). However, higher and higher demands are made for the accuracy of industrial inspection in the recent years. Since a mere pixel-level centre extraction is hardly able to meet the current requirement, a more accurate subpixel-level centre line extraction for the structured light is needed.

In this work, we employ a Steger's technique [25] to obtain candidate centre points at the subpixel level. This technique gets the subpixel-level centre positions of the light stripes, using the eigenvalues and eigenvectors of the Hessian matrix. The direction of the stripe can also be derived from the Hessian matrix. The subpixel-level centre points of the light stripe are calculated as Taylor expansion in the normal-vector direction. However, both true and redundant (artefact) sublevel centre points can be obtained with the Steger's method, thus degrading the detection 
procedure. To improve this point, we suggest comparing the subpixel positions extracted using the Steger's method with the pixel-level centre positions extracted as described in the Section 2.2. Only subpixel centre points located within the pixel-level centre position are regarded as true subpixel-level points, and the rest of the subpixel centre points must be abandoned. In this way one can be obtain the subpixel-level centre line.

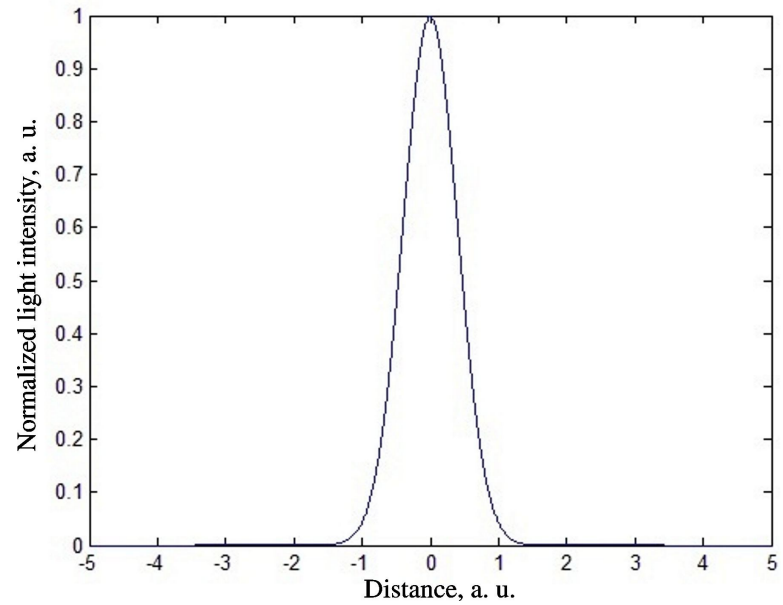

Fig. 3. Normalized light intensity distribution of the light stripe.

The procedures performed according to our method can be summarized as follows:

(1) Preprocessing. The original image is enhanced with our adaptive power-law transformation, where the exponent is obtained adaptively, using a polynomial function of the signal-to-noise ratio of the original image;

(2) Pixel-level centre line extraction. An improved Canny operator is used to extract the edges of the optical stripes so that the pixel-level centre is obtained;

(3) Extraction of subpixel-level candidate centre points. The Steger's method is used to extract the candidate subpixel-level centre points, where both true and false sub-level points are obtained;

(4) Extraction of subpixel-level centre line. The results obtained at the steps (2) and (3) are combined. A set of subpixel centre points inside the pixel-level centre line is regarded as the true subpixel-level centre line, and the rest of points are discarded.

\section{Experimental results and discussion}

To examine the technique suggested above, we have performed experiments, extracting centre positions of the structured light stripes under different conditions. The main components of our experimental system are a laser projector, a camera, a tripod, and a computer. A red laser with the wavelength $650 \mathrm{~nm}$ is employed to irradiate the object surface projected by a laser projector. We use a camera FV-G200B1 Ricoh, Japan, with camera lens having the focal length of $16 \mathrm{~mm}$. The configuration of our computer is as follows: two 1.6 GHz CPUs and 2 GB memory.

The Otsu's method, the median filter and our adaptive method have been tested in preprocessing three groups of images, which contain structured light projected on three different textures of objects. Fig. 4 shows the original images. Here panels (a) and (b) correspond to projection of the structured light onto different plaster walls, and panel (c) to its projection onto a rail-test block. Fig. 5, Fig. 6 and Fig. 7 display the images preprocessed using respectively the median filter, the Otsu's method and the adaptive method proposed in the present work. 

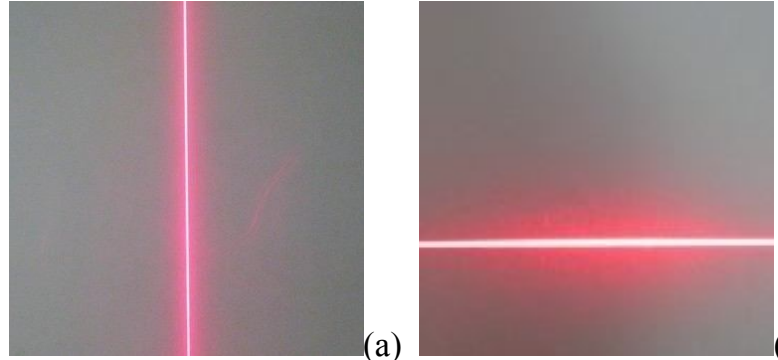

(a)
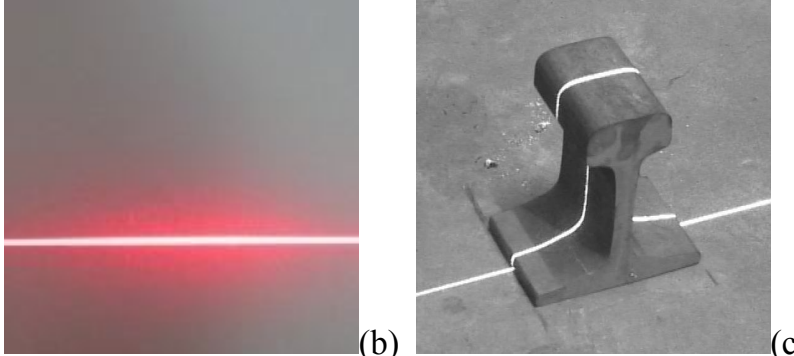

Fig. 4. Original images.
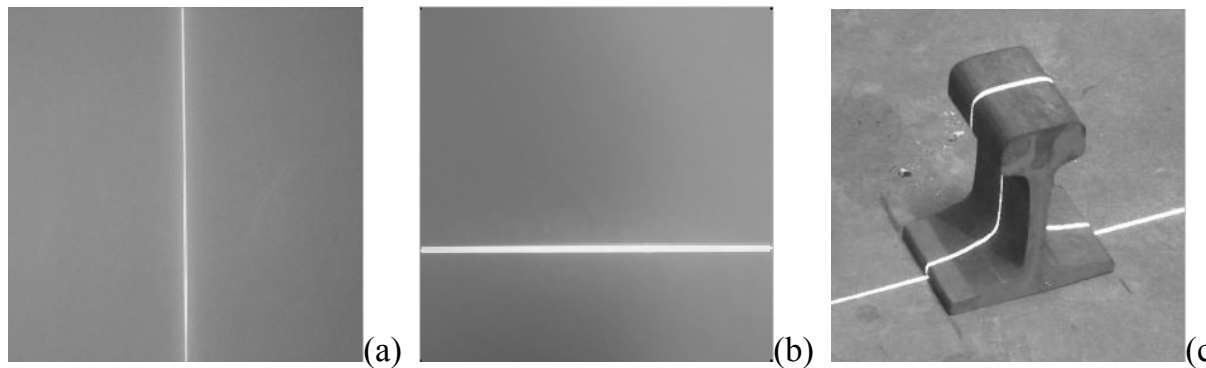

Fig. 5. Original images processed with the median filter.
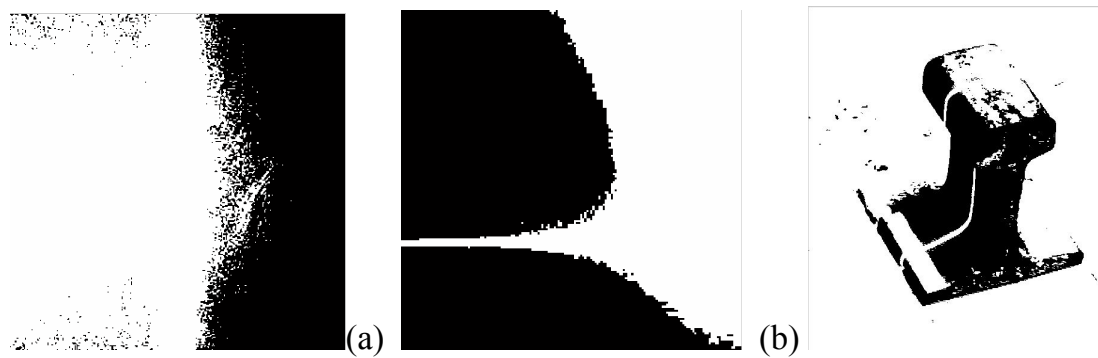

(b)

(c)

Fig. 6. Original images processed with the Otsu' method.
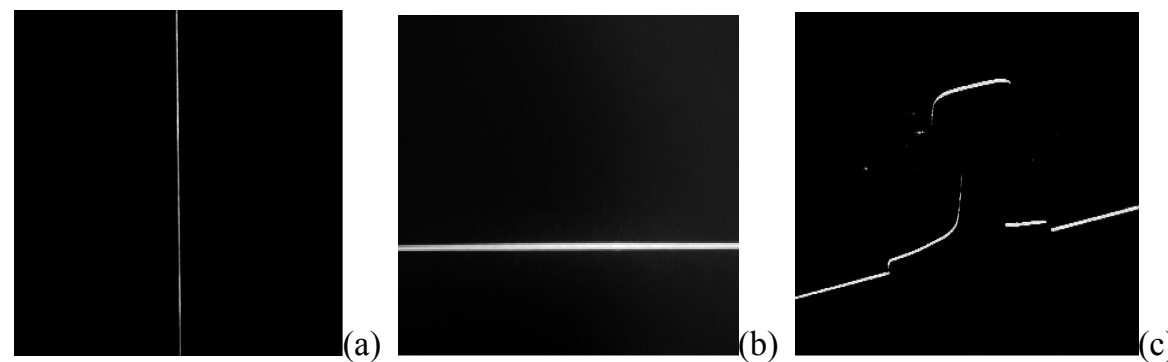

Fig. 7. Original images processed with our adaptive method.

Although the median filtering is good at processing scattered-light images, it is not good at correcting the images by uneven illumination and it cannot improve the contrast (cf. Fig. 4 with Fig. 7). The Otsu's method is not suitable for the images taken under uneven illumination. Finally, the method developed in this study can handle efficiently the problems caused by uneven illumination and improve the contrast between the light stripes and the background.

In our next experiments dealing with dynamic rail detection, we have taken 50 dynamic frame images for different rail positions and under different radiant illuminations. These images 
have been processed to evaluate the accuracy of our method. Fig. 8 gathers the signal-to-noise ratios for all of these 50 frame images, according to which they can be subdivided into 'discernible' and 'unidentifiable'. Namely, when the signal-to-noise ratio of the image is higher than $1.3 \mathrm{~dB}$, the light-stripe detection rate for our method exceeds $95 \%$ and the image can be qualified as discernible.

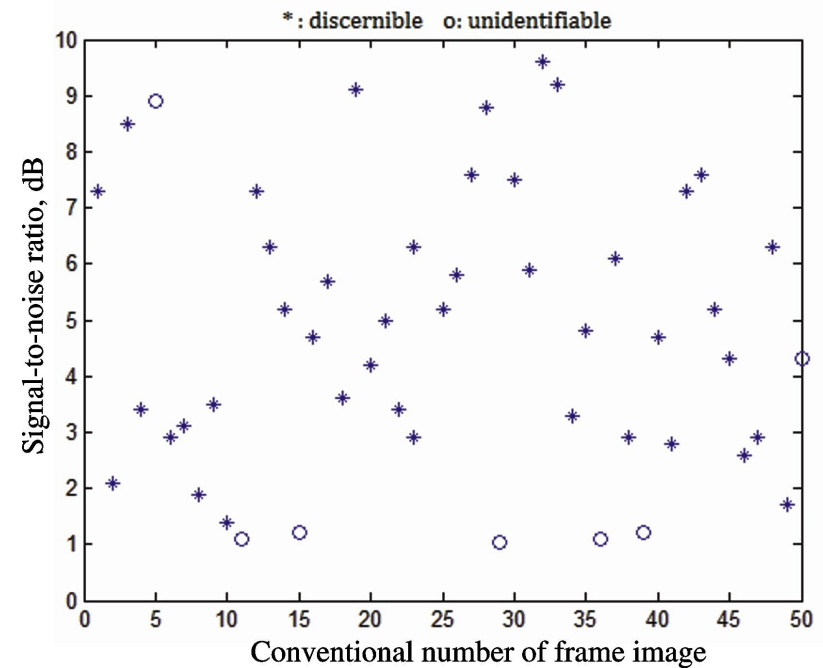

Fig. 8. Signal-to-noise ratios obtained with our method for 50 dynamical frame images, and division of those images into 'discernible' and 'unidentifiable' (see the text).

Fig.9 and Fig. 10 illustrate some specific data obtained for an image selected randomly from the initial set of the frame images. Here the original image is represented in Fig. 9, while Fig. 10 shows the subpixel-level centres of the light stripe, which are extracted with the adaptive method. In order to test the accuracy of our method in the task of dynamic detection of rail, the centre position of the image shown above is calculated using our method. Notice that the Steger's method, like our method, can also reach the subpixel-level accuracy. However, it produces several false centres or misses the true centres in some transverse section of the light stripe. At the same time, our method copes with this problem. Hence, the improvements suggested in the present work can greatly enhance the robustness and practicability of the centre-extraction methods.

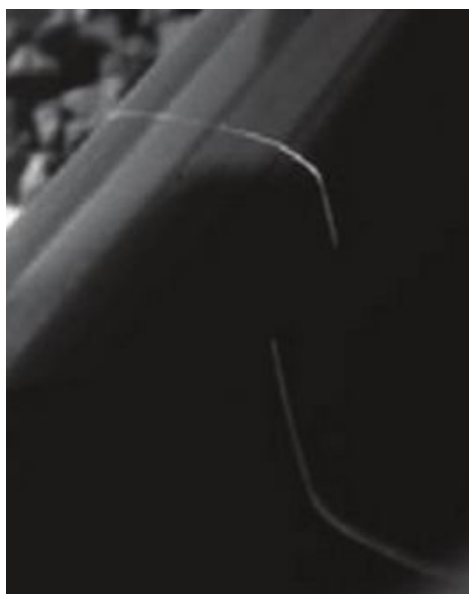

Fig. 9. Original image. 


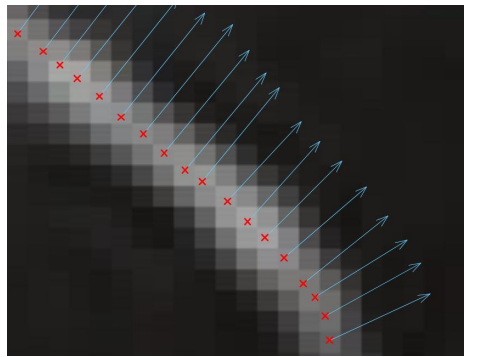

Fig. 10. Amplified image of subpixel-level centres of the light stripe obtained from the image shown in Fig. 9.

\section{Conclusion}

In this work we have suggested a novel centre-extraction method for the structured light stripes, which is suitable under the conditions of high environmental illumination. The key features of our approach are as follows: (i) the adaptive power transform based on the signal-to-noise ratio is used to improve the contrast, (ii) the adaptive Canny operator based on the upper and lower thresholds is implemented to detect the edges of the structured light and, finally, (iii) a two-step modified Steger's method based on the Hessian matrix is suggested to retrieve rapidly the subpixel-level centre points.

Our experiments have demonstrated that (i) the method can efficiently deal with the influences of excessive environmental illumination, (ii) it can obtain the structured light centre rapidly and precisely, and (ii) it is suitable for real-time industrial measurements. In particular, our method can be employed when processing the images with low contrasts and uneven lighting. Such images are often generated under the conditions of high radiant illumination and in the case of complex surface textures of the objects under study.

\section{Acknowledgement}

This work is supported by the Natural Science Fund of Hubei Province (Grant No. 2014CFB268).

\section{References}

1. Pérez L, Rodríguez Í, Rodríguez N, Usamentiaga R and García D F, 2016. Robot guidance using machine vision techniques in industrial environments: a comparative review. Sensors. 16: 335 .

2. Cho M and Shin D, 2013. Depth resolution analysis of axially distributed stereo camera systems under fixed constrained resources. J. Opt. Soc. Korea. 17: 500-505.

3. Son T, Lee J and Jung B, 2013. Contrast enhancement of laser speckle contrast image in deep vasculature by reduction of tissue scattering. J. Opt. Soc. Korea. 17: 86-90.

4. Tsukada T, Nakano T, Yamamoto S, Matsuo H, Iwata A, 1999. A method for measuring the 3-D shape of objects with non-uniformly reflective surfaces. Electric. Engineering in Japan. 126: $40-47$.

5. Larsson S and Kjellander J A P, 2006. Motion control and data capturing for laser scanning with an industrial robot. Robot. Autonom. Syst. 54: 453-460.

6. Liu K, Wang Y C, Lau D L, Hao Q and Hassebrook L G, 2010. Dual-frequency pattern scheme for high-speed 3-D shape measurement. Opt. Express. 18: 5229-5244.

7. Jun Cheng, Shiguang Zheng and Xinyu Wu, 2013. Structured light-based shape measurement system. Signal Process. 93: 1435-1444.

8. Leng $\mathrm{H}, \mathrm{Xu} \mathrm{C}$, Feng $\mathrm{Z}$ and Xiao D, 2008. A method for extracting the center of ring- 
structured-light stripe. Second International Symposium on Intelligent Inform. Technol. Appl. IITA'08. 2: 906-910.

9. Nobuyuki Otsu, 1979. A threshold selection method from gray-level histograms. IEEE Trans. Syst. Man. Cyber. 9: 62-66.

10. Milanfar P, 2013. A tour of modern image filtering: New insights and methods, both practical and theoretical. IEEE Sign. Process. Mag. 30: 106-128.

11. Yeong-Taeg Kim, 1997. Contrast enhancement using brightness preserving bi-histogram equalization. IEEE Trans. Consumer Electron. 43: 1-8.

12. Weihua Wang, Songlin Liu, Ming Wan, Yan He and Zengping Chen, 2015. A real-time target detection algorithm based on combination of intensity and edge for infrared search system. Proc. SPIE. 9812, MIPPR 2015: Automatic Target Recogn. and Navig. 98120S.

13. Canny J, 1986. A computational approach to edge detection. IEEE Trans. Pattern Analysis and Machine Intelligence. 8: 679-698.

14. Perona $\mathrm{P}$ and Malik J, 1990. Scale-space and edge detection using anisotropic diffusion. IEEE Trans. Pattern Analysis and Machine Intelligence. 12: 629-639.

15. Harris C and Stephens M, 1988. A combined corner and edge detector. In: Proc. Alvey Vision Conf. 147-151.

16. van de Weijer J, Gevers T and Geusebroek J M, 2005. Edge and corner detection by photometric quasi-invariants. IEEE Trans. Pattern Analysis and Machine Intellig. 27: 625630.

17. Tsai L W, Hsieh J W and Fan K C, 2007. Vehicle detection using normalized color and edge map. IEEE Trans. Image Process. 16: 850-864.

18. Chaudhuri S, Chatterjee S, Katz N, Nelson M and Goldbaum M, 1989. Detection of blood vessels in retinal images using two-dimensional matched filters. IEEE Trans. Med. Imaging. 8: $263-269$.

19. Djemel Ziou, 1991. Line detection using an optimal IIR filter. Pattern Recogn. 24: 465-478.

20. Laligant $\mathrm{O}$ and Truchetet F, 2010. A nonlinear derivative scheme applied to edge detection. IEEE Trans. Pattern Analys. and Mach. Intelligence. 32: 242-257.

21. Ke Li, Cuifang Kuang and Xu Liu, 2013. Small angular displacement measurement based on an autocollimator and a common-path compensation principle. Rev. Sci. Instrum. 84: 015108.

22. Luengo-Oroz M A, Faure E and Angulo J, 2010. Robust iris segmentation on uncalibrated noisy images using mathematical morphology. Image Vision Comp. 28: 278-284.

23. Guosheng Xu, 2009. Sub-pixel edge detection based on curve fitting. In: Proc. Second Intern. Conf. on Inform. Comp. Sci. IEEE, 373-375.

24. Goshtasby A and Shyu Hailun, 1995. Edge detection by curve fitting. Image Vision Comput. 13: $169-177$.

25. Steger C, 1998. An unbiased detector of curvilinear structures. IEEE Trans. Pattern Analysis and Machine Intelligence. 20: 113-125.

26. Li Qi, Yixin Zhang, Xuping Zhang, Shun Wang and Fei Xie, 2013. Statistical behavior analysis and precision optimization for the laser stripe center detector based on Steger's method. Opt. Express. 21: 13442-13449.

27. Lemaitre C, Perdoch M, Rahmoune A, Matas J and Miteran J, 2011. Detection and matching of curvilinear structures. Pattern Recogn. 44: 1514-1527.

28. Linglong Lin, Yuntao Song, Yang Yang, Hansheng Feng, Yong Cheng, Hongtao Pan 2015. Computer vision system R\&D for EAST articulated maintenance arm robot. Fusion 
Engineering and Design 100: 254-259.

29. Deriche R, 1987. Using Canny's criteria to derive a recursively implemented optimal edge detector. Int. J. Comp. Vision. 1: 167-187.

Zhixin Hu, Hongtao Zhu, Ming Hu and Yong Ma. 2017. Adaptive centre extraction method for structured light stripes. Ukr.J.Phys.Opt. 18: 9 - 19.

Анотація. У системах зору, щчо працюють у структурованому світлі, одним із ключових моментів у виріменні задачі вимірювань є точне визначення позицій иентра світлої смуги. Надмірна текстурованість поверхні проектованих об 'єктів і висока освітленість зазвичай понижують відповідну точність. Для вирішення ичих проблем запропоновано адаптивний метод екстракиії ичентра. По-перше, він підвищує контраст зображення за допомогою нового адаптивного степеневого перетворення, заснованого на порозі. По-друге, иентральні точки на рівні пікселів отримують за допомогою адаптивного методу Кенні з подвійним порогом для виявлення краю. Нарешті, центральні точки на рівні субпікселів знаходять за допомогою матрицю Гессе для обмеженої кількості пікселів. Наші експерименти довели надійність і практичну виправданість иъього методу, який ефективно працює з ускладненими поверхневими текстурами проектованих об'єктів, а також за умов високої освітленості. 